\title{
Os grandes empreendimentos e as comunidades tradicionais: o caso da comunidade de Mundaú - Trairí, Ceará.
}

\author{
The big enterprises and the traditional communities: the case of Mundaú's community - Trairí, Ceará. \\ Jocicléa de Sousa Mendes', Adryane Gorayeb², Yanna Lira Machado³, Edson Vicente da Silva ${ }^{4}$ \\ ' Aluna de doutorado no Programa de Pós-Graduação em Geografia, Universidade Federal do Ceará, Fortaleza - CE - Brasil \\ 2,4 Professor Doutor do Departamento de Geografia, Universidade Federal do Ceará, Fortaleza - CE - Brasil \\ ${ }^{3}$ Aluna de graduação em Geografia, Universidade Federal do Ceará, Fortaleza - CE - Brasil
}

\section{Resumo}

O litoral nordestino do Brasil vem sendo ocupado por grandes empreendimentos, todos justificados como geradores de emprego e de melhoria na qualidade de vida das comunidades tradicionais. No Ceará, parte desses empreendimentos foi locada em comunidades tradicionais e influenciou no modo de vida da população. O objetivo do estudo foi realizar uma análise da implantação de empreendimentos e dos impactos causados por eles nessas comunidades e, sobretudo, em uma APA. Quanto aos aspectos metodológicos da pesquisa, foram utilizadas observações diretas, efetivadas através de trabalhos de campo (período de 2010 a 2013), e análise documental da legislação vigente para a área. O resultado da investigação constatou que a APA do Estuário do Rio Mundaú, situada no litoral oeste cearense, mesmo sendo uma área protegida e amparada pela legislação, não tem garantia de uma preservação adequada e de um manejo que assegurem a manutenção da qualidade do ambiente e do modo de vida da comunidade. Ocorreram mudanças significativas nas atividades tradicionais da população. Através da privatização de áreas comuns (campos de dunas, áreas de manguezal, faixa de praia) as comunidades são impedidas de utilizar locais que faziam parte de suas rotinas: as áreas de pesca e mariscagem, antes de uso comum, hoje são ocupadas pela carcinicultura; os campos de dunas, destinados ao lazer e ao plantio agrícola sazonal (zonas de deflação) são ocupadas pelo parque eólico; por fim, a faixa de praia está sendo gradualmente ocupada pelos empreendimentos hoteleiros. Esses empreendimentos são responsáveis por diversos problemas ambientais e pela alteração total da dinâmica natural. Entre os impactos sociais destacam-se: a expulsão de marisqueiras e pescadores de suas áreas de trabalho; a privatização de áreas públicas e de lazer; a ilusão de empregos fixos; o aumento da prostituição e do uso de drogas na comunidade. Conclui-se que as comunidades estão sendo expulsas de suas áreas e muitas vezes são coniventes com o fato, pelo poder de convencimento que os empreendedores possuem.

Palavras-chaves: Grandes Empreendimentos, Impactos Socioambientais, Comunidades Tradicionais.

\begin{abstract}
The seacoast of Brazil's northeast has been occupied by a large number of enterprises, all of which are justified as being sources of jobs and improvement on the quality of life of the local communities. In Ceará, some of these enterprises were located in traditional communities and they have influenced the lifestyle of the population. The purpose of this study was to work out an analysis of the implementation of enterprises and its impacts in these communities and, mainly, in an APA. As to the metodologic aspects of the research, it was used direct observations, which were made through fieldwork (from 2010 to 2013), in addition to the documental analysis of the legislation in force. The result of the investigation found that the APA of the estuary of Mundaú's river, which is situated on the east seaside of Ceará, doesn't have guarantees of an adequate preservation and of a management that can assure the maintenance of the quality of the enviroment and of the community lifestyle, even being an protected area and supported by the legislation. There have been significant changes on the traditional activites of the population. Through the privatization of common áreas (dune fields, mangrove areas, stretches of beach) the local communities are prevented from using areas which used to form part of their routine. Fishing and shellfish collection areas, which were before communal areas, today are used for shrimp farming. The dune fields, areas destined for leisure and the agricultural plantation seasonal (deflation zones), are occupied by a big wind farm and, lastly, a stretch of beach is being gradually occupied by hotelier ventures. These ventures, which are responsible for many environmental problems, have totally changed the natural dynamic. Amongst the social impacts, it can be quoted: the expulsion of fishermen from their original work areas; the privatization of public places and of leisure areas; the illusion of fixed employments; the rise of prostitution and the use of drugs in the community. The conclusion is that the communities are being excluded from their original area and many times they are colluding with the fact due to the power of persuasion that the entrepreneurs have.
\end{abstract}

Keywords: River basin; border; water resources; territory. 


\section{INTRODUÇÃO}

As regiões litorâneas do Ceará, Nordeste do Brasil, apresentam belezas cênicas e um elevado valor paisagístico e cultural e são as áreas mais ocupadas em todo o território do estado. São sistemas ambientais dinâmicos e frágeis, altamente vulneráveis às atividades antrópicas e impactados por grandes empreendimentos (VASCONCELOS, 2005; GORAYEB; SILVA; MEIRELES et al., 2005; MEIRELES, 2011).

No Ceará, grande parte $(47,1 \%)$ das Unidades de Conservação (UCs) está localizada no litoral (OLIVEIRA, 2011). Essas UCs são criadas com o intuito de proteger o ambiente e ordenar o seu uso (OLIVEIRA; MATTOS, 2007), todavia observa-se a existência de muitos problemas, tais como ocupação em áreas indevidas, instalação de grandes empreendimentos, destinação inadequada de resíduos sólidos, falta de saneamento básico, bem como práticas do turismo convencional (turismo de massa). Conforme Benthonico (2009), esses transtornos ocorrem por variados motivos: falta de gerenciamento, não cumprimento de leis, falta de um plano de manejo ou mesmo ausência de ações efetivas de gestão por parte do poder público.

Na Área de Proteção Ambiental (APA) do Estuário do Rio Mundaú, localizada no litoral oeste do estado do Ceará, evidencia-se o não cumprimento da legislação vigente. A área está sendo gradativamente ocupada por grandes empreendimentos, todos justificados como geradores de emprego e de melhoria na qualidade de vida das comunidades tradicionais (SIMAS; PACCA, 2013; PRIMAVERA, 2005). Marra (2011) afirma que para se proporcionar qualidade de vida à sociedade é necessária a proteção da natureza, sobretudo da cultura, elementos que muitas vezes não são considerados na implantação de grandes atividades empreendedoras se revelam em forma de problemas socioambientais e de conflitos na comunidade (LITTLE, 2006).

Os empreendedores possuem um alto poder de persuasão e, através das atividades compensatórias, vão ganhando espaço e a confiança das comunidades, para assim se instalarem sem a resistência da população.

Vários membros da comunidade acreditam que esses empreendimentos são muito importantes para a região e formadores de bons empregos para comunidade; porém, o que se percebem são empregos de baixa remuneração que distanciam os jovens das atividades tradicionais, além de impactar o meio ambiente e prejudicar a prática de um turismo sustentável, uma vez que ocorre a perda de belezas paisagísticas naturais.

O assunto é discutido por autores como Zografos; Soladié (2011), Meireles et al. (2007), Dias (2012), Primavera (2005); Oliveira (2011); Panizza; Fournier (2008), entre outros.

\subsection{Caracterização socioambiental da comunidade de Mundaú}

A bacia hidrográfica do rio Mundaú se insere na porção nordeste da Bacia do Litoral, abrange uma área de, aproximadamente, $985 \mathrm{~km} 2$ e drena parte dos municípios de Uruburetama (90\%), Tururu (41\%), Itapipoca (37\%) e Trairi (37\%), incluindo apenas as sedes municipais de Tururu e Uruburetama. Esse último município abriga as suas principais nascentes hídricas.

A área de estudo compreende a comunidade de Mundaú, localizada no município de Trairi, à margem direita do estuário da bacia do rio Mundaú, que foi decretada como APA através do Decreto no 25.414, de 29 de março de 1999 (Figura 1). Atualmente, Mundaú possui 891 famílias e 3.825 habitantes ${ }^{1}$. Muitas famílias vivem exclusivamente da pesca e outras alternam a atividade com ocupações diversas, com destaque para os pequenos comércios. Outra atividade econômica significativa na comunidade diz respeito à produção de renda de bilro confeccionada pelas mulheres, que assim contribuem para o sustento familiar. A atividade artesanal é efetivada nos finais da tarde, quando é comum encontrar grupos de mulheres nas calçadas fazendo renda e conversando.

\section{METODOLOGIA}

A análise documental se deu através das leituras do Sistema Nacional de Unidades de Conservação (Snuc), criado pela Lei 9985/2000); do Decreto Estadual no 25.414, de 29 de março de 1999,

1 Dados coletados com as agentes de saúde da comunidade. 


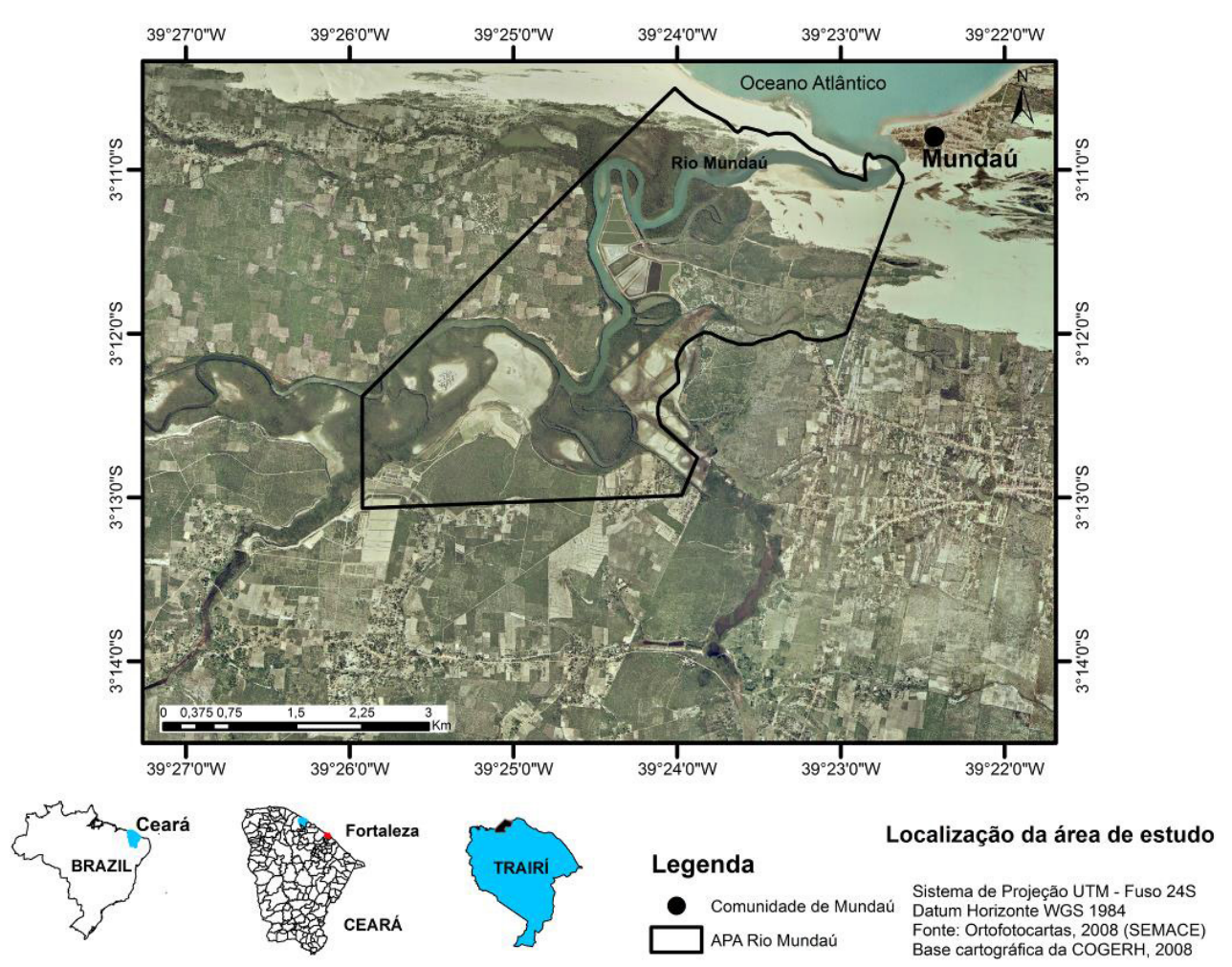

Figura 01 - Localização da área de estudo

que instituiu a criação da APA; do Plano de Manejo da APA, documento que traça as diretrizes de uso da área; do Decreto no 6040, que instituiu a Política Nacional de Desenvolvimento Sustentável dos Povos e Comunidades Tradicionais.

Os trabalhos de campo ocorreram entre os anos de 2010 e 2013. Visitaram-se toda a área da APA e as comunidades do entorno, analisando todos os empreendimentos existentes, acompanhando toda a implantação do parque eólico e os impactos gerados, e observando a relação da comunidade com a área e com o empreendimento.

\section{PROBLEMÁTICAS COMUNITÁRIAS}

A APA do Estuário do Rio Mundaú foi criada tomando em consideração as suas peculiaridades ambientais, a natural fragilidade do equilíbrio ecológico local, assim como a necessidade de conscientização da população acerca da preservação da área, em busca de um desenvolvimento sustentável.

O Decreto n. 25.414 relata as atividades que passam a ser proibidas na APA:

a) A implantação ou ampliação de atividades potencialmente poluidoras ou degradadoras, capazes de afetar os mananciais de água, as formas do relevo, a cobertura florestal, o solo e o ar. b) A realização de obras de terraplanagem e a abertura de estradas, bem como sua manutenção, quando essas iniciativas importarem em sensíveis alterações das condições ecológicas.

c) A derrubada de vegetação de preservação permanente definida nos arts. 20 e 30 da Lei Federal no 4.771 , de 15 de setembro de 1965 .

d) Qualquer forma de utilização que possa poluir ou degradar os recursos hídricos abrangidos pela APA, como também o despejo de efluentes, resíduos ou detritos, capazes de provocar danos ao meio ambiente.

Além das atividades apresentadas no Decreto como proibidas, existem outras diretrizes traçadas pelo Plano de Manejo, documento exigido pela Lei no 9.985, de 18 de julho de 2000 (BRASIL, 2000), 
que deve ser elaborado com até 5 anos após a criação da unidade. O documento traça diretrizes para o convívio da população com o ambiente e trata de aspectos econômicos e sociais da área, apontando os usos que podem ser realizados na área para o alcance de todos os objetivos da criação da unidade.

O Plano de Manejo da APA propõe a delimitação de zonas de uso, e a definição dessas zonas ocorre com o propósito de proporcionar um manejo mais eficaz e adequado.

As zonas estabelecidas no Plano de Manejo da APA do Estuário do Rio Mundaú são compostas pela Zona de Preservação Ambiental, pela Zona de Recuperação Ambiental e pela Zona de Uso Sustentável. A divisão em zonas objetiva ordenar o uso e promover uma melhor qualidade de vida.

O plano propõe algumas atividades que visam promover o respeito aos usos dessas zonas, bem como o cumprimento da legislação, podendo-se destacar: divulgação da legislação ambiental vigente na APA; realização de fiscalização e monitoramento permanente; mobilização das comunidades residentes na APA e no seu entorno, alertando-as dos locais que devem ser preservados; definir responsabilidades dos órgãos ambientais no que tange ao licenciamento de obras, controle e fiscalização (CEARÁ, 2005).

No Plano de Manejo da APA está claro o impedimento da realização de qualquer empreendimento que modifique o modo de vida das comunidades tradicionais, o relevo e a hidrodinâmica e morfodinâmica do litoral. O documento ressalta a punição em casos de crimes ambientais que venham a acontecer na área, todavia não elimina algumas práticas indevidas.

Convém por fim fazer referência ao tipo penal previsto no art. 40 da Lei de Crimes Ambientais - Lei no 9.605/98 -, que define como crime, punível com pena de reclusão, de um a cinco anos, $\mathrm{o}$ ato de causar dano direto ou indireto a qualquer unidade de conservação, agravando-se a pena se houver prejuízo a espécies, animais ou vegetais, ameaçadas de extinção (CEARÁ, 2005).

Contrariando os documentos mencionados, podem-se apresentar algumas atividades em desacordo e que estão acontecendo sem planejamento, ocasionando impactos socioambientais, influenciando diretamente no modo de vida das comunidades tradicionais. Encontram-se, na área, estabelecimentos hoteleiros de médio porte, atividades de carcinicultura e um parque eólico, o mais recente empreendimento local, iniciativas que proporcionam mudanças significativas nas comunidades em que estão instaladas.

Os empreendimentos hoteleiros, construídos em áreas de grande instabilidade, um deles erguido sobre eolianitos, dunas reliquiárias (Figura 2). Carvalho et al., 2008; Meireles; Gurgel Jr. (1994) asseguram que esses depósitos estão ligados a regressões marinhas, o que levou à cimentação dos grãos de quartzo por biodetritos, constituindo uma crosta superficial no topo das dunas. Diante da sua importância e de suas características peculiares, esses ambientes deveriam ser preservados, o que não ocorre na área.

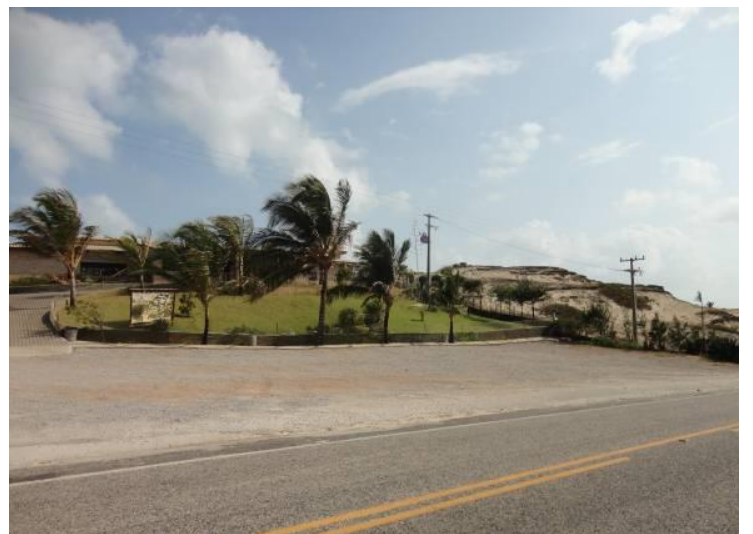

Figura 2 - Pousada construída sobre eolianitos

Na APA de Mundaú, a carcinicultura está instalada em manguezais na zona estuarina. Esse ecossistema desenvolve-se desde próximo à desembocadura do rio até onde o rio recebe a influência das marés. O manguezal é de suma importância para a estabilidade da geomorfologia costeira, para a conservação da biodiversidade e para a manutenção das atividades pesqueiras, que sustentam centenas de moradores do litoral cearense (CICIN-SAIN; KNECHT, 1998; ALONGI, 2002; MOLNAR et al., 
2013; THOMAS et al., 2010; MEIRELES, 2002).

Os manguezais foram definidos - pela Lei no 4.771, de 15 de setembro de 1965, que instituiu o Código Florestal, e pela Resolução no 303, de 20 de março de 2002, criada pelo Conselho Nacional do Meio Ambiente - como Área de Preservação Permanente (APP), por apresentar grande fragilidade e importância ecológica, não podendo, assim, ser ocupada por empreendimentos que causem algum dano à dinâmica natural.

No entanto, atualmente, no mundo, bem como na área pesquisada, essas unidades estão sendo ocupadas gradativamente pela carcinicultura, atividade danosa ao geoecossistema (DIAS; SOARES; NEFFA 2012; VALIELA; BOWER E YORK, 2001; PRIMAVERA, 2005; OLIVEIRA; MATTOS, 2007). Entre os principais danos, Meireles (2004) e Primavera (2005) apontam: o soterramento de gamboas; a expulsão de marisqueiras e pescadores de suas áreas de trabalho; a contaminação das águas por efluentes de viveiros; a fuga de camarões exóticos para ambientes fluviais e fluviomarinhos; a impermeabilização do solo.

A área ocupada pela carcinicultura, em Mundaú, compreende 4,7 hectares. Em relação a outros estuários, a extensão não é tão representativa, entretanto gera os mesmos problemas. Notou-se, em um período de dois meses, um aumento no número de bombas de captação nas margens do rio para a alimentação dos viveiros de camarão. Havia, em dezembro de 2010, apenas uma bomba de captação de água para os viveiros, e em fevereiro de 2011 já existiam quatro (Figura 3).

Relatos de moradores expõem a diminuição do pescado após a instalação da carcinicultura, além da expulsão das marisqueiras de suas áreas tradicionais de coleta. Esse fato causou alteração no modo de vida da comunidade, afetando, inclusive, o direito de ir e vir dos habitantes. As áreas de mariscagem eram de livre acesso, mas, com a instalação do empreendimento, parte dessas áreas foi privatizada, tornando proibido o acesso, inclusive das marisqueiras, pessoas que culturalmente faziam uso da área, iniciativa que violou o inciso XV do art. 3 do Decreto no 6040 de 7 de fevereiro de 2007, que instituiu a Política Nacional de Desenvolvimento Sustentável dos Povos e Comunidades Tradicionais (BRASIL, 2007).

Figura 3 - Bombas de captação de água para os viveiros de camarão
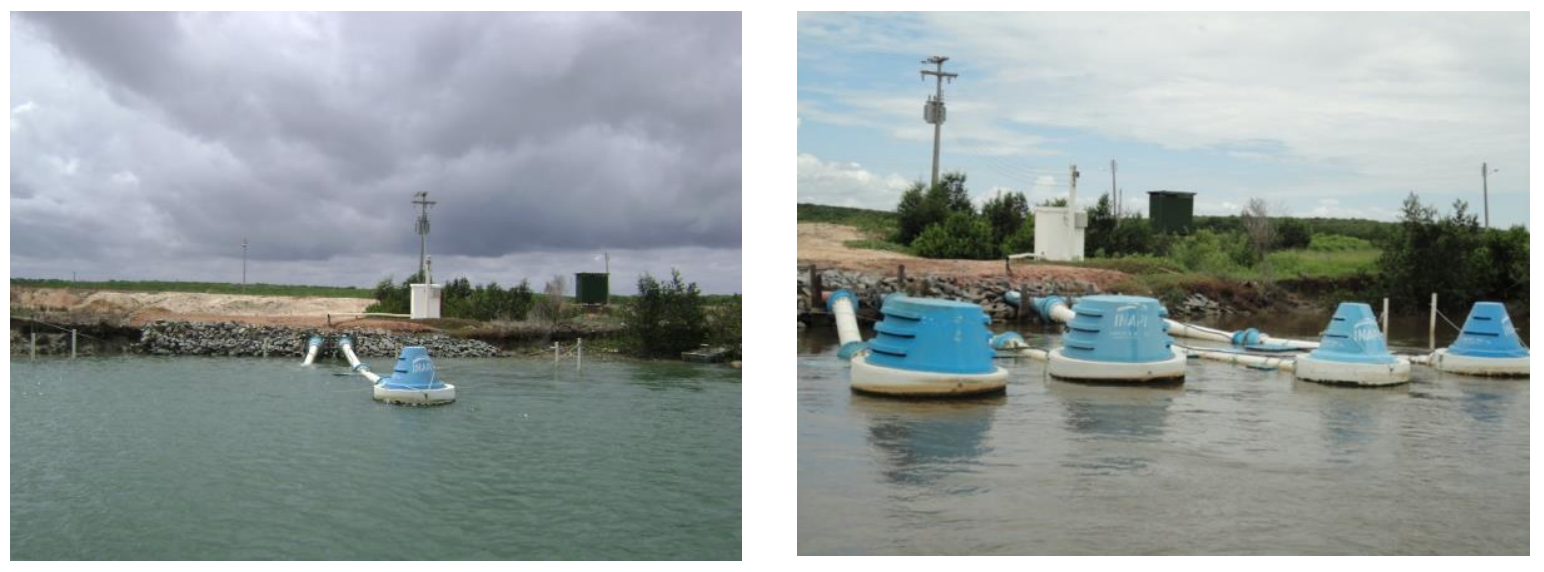

A implantação de um parque eólico é considerada um dos problemas atuais que está gerando conflitos internos na comunidade, proporcionados por divergências de opiniões: uma parte da população está a favor do empreendimento, entendido como fomentador de emprego e renda, e outra contra, entendendo a instalação e a manutenção do negócio como causadoras de problemas ambientais e sociais.

O Diário Oficial da União (10/08/2010), Seção 1, p. 158, afirma que a potência da usina será de 29.9 Mw e terá a garantia física de energia (MWmed) de 14.1. A obra já está em andamento e é sabido que ela causa grandes transtornos socioambientais para a comunidade.

Sabe-se que esses empreendimentos são tidos como geradores de energia limpa e como obras de baixo impacto, contudo sua instalação em áreas instáveis gera efeitos negativos ao ambiente, alterando toda a dinâmica natural da área. Para a implantação de um empreendimento desse porte é necessária a abertura de vias de acesso, tendo como medidas o corte de dunas, a terraplanagem, o soterramento de lagoas interdunares, o desmatamento de dunas fixas e a impermeabilização de parte do terreno (Figura 4). 


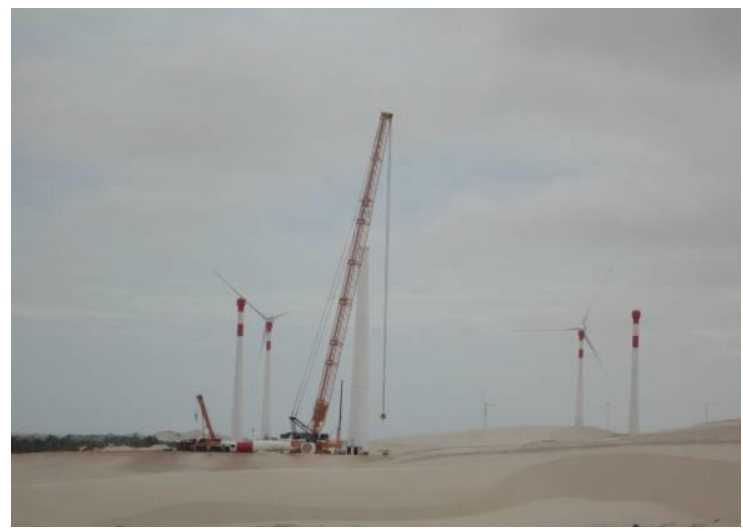

Figura 4 - Instalação do parque eólico de Mundaú

Meireles (2011) cita alguns impactos causados por obras desse porte, dos quais se destacam: alterações topográficas e morfológicas; aterramento de dunas fixas e eliminação de sua vegetação; alteração do nível hidrostático do lençol freático, o que pode influenciar no fluxo de água subterrânea e na composição e abrangência espacial das lagoas interdunares; secção das dunas, lagoas e planície de aspersão eólica; mudança na dinâmica eólica, acelerando o processo erosivo; impermeabilização do solo, que pode alterar o nível de água doce nos aquíferos.

O parque eólico está sendo instalado no campo de dunas situado na margem direita do rio Mundaú. Zona conhecida como bypass, Meireles; Silva e Thiers (2006) alertam que construções indevidas e outros tipos de uso nessa zona representam obstáculos, inibem e barram o fluxo de sedimentos, interferindo no transporte e na reposição de sedimentos, alterando o balanço sedimentar, influenciando a dinâmica morfológica da área e acentuando os efeitos de erosão.

A comunidade divide opiniões sobre os benefícios e os malefícios que o empreendimento energético vem ocasionando na área, como já foi dito. Para muitos, o empreendimento trouxe emprego; melhores condições de vida; oportunidades de qualificação, caso específico das rendeiras, que foram beneficiadas com a promoção de cursos de aperfeiçoamento de suas peças, através de designers e economistas que as auxiliaram a valorizar seus produtos tornando-os mais atraentes e competitivos. Para outros, existe o entendimento de que realmente parte da comunidade foi beneficiada com empregos e passou a receber salários fixos, fato que despertou na população um desinteresse por atividades tradicionais como a pesca - abandonada por muitos dos que se determinaram a ingressar na empresa. No entanto, com a finalização de etapas da construção do empreendimento, o serviço de parte dos empregados já não era necessário, de forma que a oferta de emprego fixo e de melhores condições de vida transformou-se em desemprego e falta de perspectiva entre alguns membros da comunidade.

A instalação do parque eólico gerou ainda outros problemas, alguns deles semelhantes àqueles criados pelos demais empreendimentos encontrados na área e já relatados, como a privatização de áreas comuns da comunidade. No caso do parque eólico, a questão centraliza-se na ocupação do campo de dunas, áreas destinadas ao lazer e ao plantio sazonal (zonas de deflação), o que atualmente resultou no impedimento da comunidade de transitar pela área.

Diante do exposto, compreende-se que a instauração dos empreendimentos na área origina e fortalece problemas socioambientais, contribuindo para a descaracterização das práticas tradicionais dessas áreas. É importante destacar que o estabelecimento dessas iniciativas empreendedoras vai gerando, ao longo do tempo, um novo comportamento social, proporcionado por uma nova dinâmica na área, na qual se tem fluxo intenso de pessoas diferentes, no caso os funcionários dos empreendimentos e turistas que transitam pela comunidade, o que traz graves consequências como o aumento da geração de resíduos sólidos e efluentes; o crescimento da violência; o tráfico de drogas e a prostituição, problemas já identificados na área.

Em face do que foi evidenciado, entende-se que as comunidades prejudicadas pelos citados empreendimentos vão se adequando às dificuldades encontradas e passam a conviver com a nova realidade. É de fundamental importância a adoção de práticas educativas com a comunidade, com o intuito de discutir e construir o conhecimento no que concerne à problemática socioambiental bem como aos direitos e deveres de todos. Nesse sentido, pode-se usar a concepção de Reigota (2006, p. 58) sobre educação ambiental, definida como uma "ampliação da participação política dos cidadãos". 
Pode-se afirmar que uma alternativa para minimizar parte dos problemas dessas comunidades seria o acompanhamento contínuo, através de ações educativas, que proporcione informação diversa para a comunidade e contribua para a fiscalização.

Vale ressaltar, ainda, que essas medidas devem ter caráter preventivo (anterior à instalação de empreendimentos), no entanto o que se nota é a efetivação de parte dessas ações na qualidade de medidas compensatórias, pois os empreendedores promovem palestras, cursos de reciclagem e geração de renda para a população como forma de "convencimento". A pesquisa constatou que parte da comunidade considera os empreendimentos como algo positivo para área, sempre com base nessas medidas compensatórias, medidas essas que muitas vezes deveriam fazer parte dos serviços oferecidos pelo governo.

O governo, sobretudo o órgão responsável pela APA do Estuário do Rio Mundaú, deve atender toda a população da área bem como consolidar a fiscalização com objetivo de cumprir com a legislação vigente e assegurar à população a continuidade dessas determinações. A educação e os costumes tradicionais são essenciais para a o equilíbrio de um ambiente e para um desenvolvimento sustentável local.

\section{CONCLUSÕES}

Diante dos fatos apresentados, averigua-se que a comunidade de Mundaú, mesmo sendo uma área protegida e amparada pela legislação, não está garantida de uma preservação adequada e de um manejo que assegurem a manutenção da qualidade do ambiente e do modo de vida da comunidade.

É evidente toda a problemática gerada pela instalação de empreendimentos na comunidade, desencadeada pela expulsão da comunidade de suas áreas, seja pela empresa hoteleira, seja pelo estabelecimento da carcinicultura e dos empreendimentos energéticos. Os empreendedores convencem a comunidade através de promessas que chamam de medidas compensatórias, com ofertas de empregos fixos - fato ilusório já que parte dos empregos é temporário - e, no caso específico de Mundaú, com a disponibilização de apoio às rendeiras, à creche e à igreja.

Releva-se que quando se fala que as medidas são "compensatórias", afirma-se que de fato elas devem compensar algo, reiterando-se, assim, a comprovação de que causam danos socioambientais às áreas que recebem empreendimentos.

Verifica-se que na APA analisada não há obediência à legislação pela observação das ocupações indevidas em APPs por atividades diversas: carcinicultura, construção de residências, entre outras. Constata-se, assim, a necessidade de consumação do Plano de Manejo e da fiscalização dessas áreas, para que se cumpra o objetivo de sua criação e para que elas passem apenas por processos evolutivos naturais.

Além das intervenções governamentais, a população deve agir como um integrante do processo, como um ente fiscalizador em sua comunidade, o que exige um conhecimento do dinamismo da paisagem e dos impactos decorrentes de uma gestão inadequada. Nesse sentido, as práticas de Educação Ambiental são de grande valia para a conscientização dessas pessoas que disseminarão o conhecimento adquirido em prol da conservação de sua comunidade.

\section{REFERÊNCIAS}

ALONGI, D. M. Present state and future of the world's mangrove forest. Environmental Conservation. v. 29, p. 331-349, 2002. Disponível em: < http://cmbc.ucsd.edu/content/1/docs/alongi\%202002.pdf>. Acesso em: 02 de junho de 2012.

BETHONICO, M. B. M; CUNHA, S. B. Gestão sustentável de unidades de conservação: o caso da APA estadual do rio Pandeiros, Minas Gerais. GEOgraphia, Rio de Janeiro, v. 11, n. 22, p. 104-127, 2009. Disponível em: <http://www.uff.br/geographia/ojs/index.php/geographia/article/view/304/261> Acesso em: $12 \mathrm{de}$ abr. 2011.

BRASIL. Congresso. Senado. Decreto No 6.040, de 7 de fevereiro de 2007, institui a Política Nacional de Desenvolvimento Sustentável dos Povos e Comunidades Tradicionais. Diário Oficial [da] República Federa- 
tiva do Brasil, Brasília, DF, 08 de fevereiro de 2007.

BRASIL. Congresso. Senado. Lei $\mathrm{n}^{\circ}$ 9.985, de 18 de julho de 2000. Regulamenta o art. 225, § 1o, incisos I, II, III e VII da Constituição Federal, institui o Sistema Nacional de Unidades de Conservação da Natureza e dá outras providências. Diário Oficial [da] República Federativa do Brasil, Brasília, DF, 18 de julho, 2000.

CARVALHO, A. M. et al. Eolianitos de Flecheiras/Mundaú, costa noroeste do estado do Ceará, Brasil -: registro ímpar de um paleo-sistema eólico costeiro. Sítios geológicos e paleontológicos do Brasil. 2008. Disponível em:< http://www.unb.br/ig/sigep/sitio118/sitio118.pdf>Acesso em: 05 de fev. 2012.

CEARÁ. Governo do Estado. Decreto n ${ }^{\circ} 25.414$, de 29 de Março de 1999. Dispõe sobre a criação da Área de Proteção Ambiental - APA do Estuário do Rio Mundaú. Diário Oficial Estadual, Poder Executivo, Fortaleza, CE, 31 de março de 1999. Disponível em: <http://imagens.seplag.ce.gov.br/PDF/19990331/do19990331p01. pdf >. Acesso em: $10 \mathrm{dez} .2010$

CEARÁ. SEMACE (Superintendência Estadual do Meio ambiente). Plano de manejo da APA do estuário do rio Mundaú. Fortaleza: SEMACE/FCPC, 2005.

CICIN-SAIN, B; KNECHT, R. W. Integrated coastal and ocean Management: Concepts and practices. Island Press, Washington, p. 543 (1998).

DIAS, H.M. ; SOARES, M.L.G. ; NEFFA, E. Conflitos socioambientais: O caso da carcinicultura no complexo estuarino caravelas - nova viçosa/bahia-brasil. Ambiente e Sociedade, vol.15(1), pp.111-130, 2012.

GORAYEB, A; SILVA, E. V; MEIRELES, A. J. A. Impactos ambientais e propostas de manejo sustentável para a planície flúvio-marinha do Rio Pacoti-Fortaleza/Ceará. Sociedade \& Natureza, Uberlândia, Minas Gerais, v.17, n. 33, p. 143-152, 2005.

LITTLE, P. E. Ecologia política como etnografia: um guia teórico e metodológico. Horizontes Antropológicos, v. 12 , n. 25 , p. 85-103, 2006.

MARRA, N. C. Identidades culturais e a sustentabilidade na criação de parques ambientais. Prisma Jur., São Paulo, v. 10, n. 2, p. 349 -367, 2011.

MEIRELES, A. J. A. et al. Integração dos indicadores geoambientais de flutuações do nível relativo do mar e de mudanças climáticas no litoral cearense. MERCATOR, Fortaleza. v. 4, n. 8, 2005. Disponível em: <http:// www.mercator.ufc.br/index.php/mercator/issue/view/M8>. Acesso em: 20 de setembro de 2011.

MEIRELES, A. J. A. Processo de licenciamento do empreendimento "COMPLEXO TURÍSTICO DE MUNDAÚ", Município de Trairí/CE. Parecer técnico elaborado para o Ministério Público Federal no Ceará (MPF/CE), 2004,59p.

A. J. A. Danos socioambientais originados pelas usinas eólicas nos campos de dunas do Nordeste brasileiro e critérios para definição de alternativas locacionais. Confins [Online], v. 11, 2011. Posto online em 03 Setembro 2011. Disponível em: <http://confins.revues.org/6970> Acesso em: 26 Abril 2013. DOI: 10.4000/ confins. 6970

MEIRELES, A. J. A; GURGEL Jr., J. B. Dinâmica costeira em áreas com dunas móveis associadas a promontórios, ao longo do litoral cearense. In: CONGRESSO BRASILEIRO DE GEOLOGIA, 38, 994, Balneário de Camboriú/SC. Anais... Balneário de Camboriú/SC, v.1, p. 403-404, 1994.

MEIRELES, A. J. A; SILVA, E. V. Abordagem geomorfológica para a realização de estudos integrados para o plenejamento e gestão em ambientes flúvio-marinhos. Scripta Nova. Revista electrónica de geografía y ciências sociales, Universidad de Barcelona, v. 6, n. 118, jul., 2002. 
MEIRELES, A. J; SILVA, E. V; THIERS, P. Os campos de dunas móveis: fundamentos dinâmicos para um modelo integrado de planejamento e gestão da zona costeira. GEOUSP - Espaço e Tempo, São Paulo, n. 20, p.101 - 119, 2006. Disponível em: <http://citrus.uspnet.usp.br/geousp/ojs-2.2.4/index.php/geousp/article/ view/310/164>. Acesso em: 13 de maio de 2011.

MOLNAR, N; WELSH, D. T; MARCHAND, C; DEBORDE, J; MERZIANE, T. Impacts os shrimp farm effluent on water quality, benthic metabolism and $\mathrm{N}$-dynamics in a mangrove forest (New Caledonia). Estuarine Coastal and Shelf Science. v. 117, p. 12-21, 2013.

OLIVEIRA, G. D; MATTOS, K. M. da C. Impactos ambientais provocados pela indústria de camarão no município de Nísia Floresta (RN). Revista Ibero-Americana de Estratégia, São Paulo, v. 6, n. 2, p. 183-188, 2007.

OLIVEIRA, I. S. R. Efetividade de manejo em áreas protegidas do Estado do Ceará: Parque Nacional de Ubajara. 2011. Dissertação (Mestrado) - Instituto Federal de Educação, Ciência e Tecnologia Programa de Pós-Graduação em Tecnologia e Gestão Ambiental, Fortaleza, 2011.

PANIZZA, A. C; FOURNIER, J. O litoral do Rio Grande do Norte: dinâmica e modelo espacial. Confins [Online], v. 3, 2008.

PRIMAVERA, J.H. Mangroves, fishponds and the quest for sustainability. Science, v.310, 2005.

REIGOTA, M. O que é Educação Ambiental. São Paulo: Brasiliense, 2006. (Coleção Primeiros Passos: 292).

SIMAS, M; PACCA, S. Energia eólica, geração de empregos e desenvolvimento sustentável. Estudos Avançados, vol.27(77), p.99, 2013.

THOMAS, Y; COURTIES, C; HELWE, Y; HERBLAND, A; LEMONNIER, H. Spatial and temporal extension of eutrophication associated with shrimp farm wastewater discharges in the New Caledonia lagoon. Marine Pollution Bulletin. v. 61, p. 387-398, 2010.

VALIELA, I; BOWEN, J. L; YORK, J. K. Mangrove forests: one of the World's threatened major tropical environments. Bioscience, v.15, n.10, p.807-815, 2001.

VASCONCELOS, F. P. Riscos naturais e antópicos na zona costeira. In: REUNIÃO ANUAL DA SBPC, 57, 2005, Fortaleza. Anais eletrônicos... São Paulo: SBPC/UECE, 2005. Disponível em: <http://www.sbpcnet. org.br/livro/57ra/programas/.htm> Acesso em: 10 jan. 2011.

VASCONCELOS, F. P. Riscos naturais e antópicos na zona costeira. In: REUNIÃO ANUAL DA SBPC, 57, 2005, Fortaleza. Anais eletrônicos... São Paulo: SBPC/UECE, 2005. Disponível em: <http://www.sbpcnet. org.br/livro/57ra/programas/CONF_SIMP/textos/fabioperdigao-riscos.htm $>$. Acesso em 10 de janeiro de 2011.

ZOGRAFOS, C; SALADIÉ, S. La ecología política de conflictos sobre energía eólica. Un estudio de caso en Cataluña. Documents d'anàlisi geográfica. vol:58, n. 1 pg:177 -192, 2012. 